\title{
Local and Regional PV Power Variability in the Northeastern U.S.: Implications for Simplified Utility Flicker Screening Analyses
}

\author{
Brice Smith and Douglas Armstead 1 \\ Department of Physics, SUNY Cortland, Cortland, New York 13045, USA \\ Correspondence should be addressed to Douglas Armstead; douglas.armstead@cortland.edu
}

Received 21 January 2020; Revised 15 March 2021; Accepted 31 March 2021; Published 1 June 2021

Academic Editor: Ciro Aprea

Copyright (c) 2021 Brice Smith and Douglas Armstead. This is an open access article distributed under the Creative Commons Attribution License, which permits unrestricted use, distribution, and reproduction in any medium, provided the original work is properly cited.

\begin{abstract}
This paper presents new evidence supporting the development of a screening threshold to evaluate the impact aggregations of solar PV facilities in the northeastern United States can have on voltage deviations in the distribution grid (often called flicker). Using measurements from solar irradiance meters and customer-sited monitoring equipment for residential and light commercial solar systems in Central New York along with data from the Measurement and Instrumentation Data Centers at the Oak Ridge National Laboratory, Elizabeth City State University, and Bluefield College, we present multiple lines of support for the adoption of a flicker screening threshold equivalent to a 5\% change in voltage resulting from a full-on to full-off transition of a solar facility. This approach is based on both the newer flicker perception limits in IEEE 1453-2015 and the previous limits derived from the flicker curves in IEEE 519-1992 and is consistent with recent draft recommendations from the Electric Power Research Institute (EPRI) for use in New York. Measurements of correlations between fluctuations at different sites along with a model for high densities of solar facilities are applied to allow the impact of multiple systems on a single feeder to be taken into account while maintaining the simplicity of a single screening threshold.
\end{abstract}

\section{Introduction}

Due to a combination of economic-, social-, and policyrelated factors, solar power has become one of the most rapidly increasing sources of power in the United States. Solar photovoltaics (PV) is now the largest source of new generating capacity added to the U.S. grid [1]. In New York, which is the focus of this work, the total installed solar capacity increased by nearly $800 \%$ between 2011 and 2016 [2]. However, in order to achieve a fully renewable energy system in a timely manner, such growth must be rapidly accelerated. According to Jacobson et al. [3], an energy system in New York powered solely by "wind, water, and sunlight" will require a total of $116,000 \mathrm{MW}$ of solar PV by 2030 . By comparison, New York has added just over $132 \mathrm{MW} / \mathrm{yr}$ of solar on average over the last five years while it would need to add more than 8,000 MW/yr to reach the target in Jacobson et al. [3].
One important obstacle to such rapid acceleration in the growth of solar power is the lack of simple, robust, and accurate ways of distinguishing where the grid has room for more solar PV and where it is already approaching its current capacity. As a result, much work is underway to develop hosting capacity analyses that will enable such high-level understanding of the grid [4-7]. From this work, it has been found that changes in the output of solar PV facilities due to intermittent cloud cover can be of particular importance to determining the grid's hosting capacity $[8,9]$.

As such, quantifying the nature of solar ramp rates as well as the correlations between ramps at nearby facilities and the resulting smoothing of output power from geographic dispersion has been a significant focus of work going back to the late 1980s [10]. In this work, some researchers have sought to model the irradiance variability by focusing on the clouds [11-16]; others by focusing on irradiance observations [17-20]; and yet others by focusing on efforts to 
quantify the smoothing in power production and decrease in correlations with increasing system size in the central U.S. [21], Germany [22], Colorado [23], and California [24].

Other approaches to estimating weather-induced solar power variability have focused on the solar installation itself and its impact on the grid. This has been done using observations from residential scale installations [25-27] as well as from larger PV plants in the western U.S. [28-30] and in Spain $[31,32]$. Current methods for simulating these results are summarized in Lave et al. [33] and more recently in Mazumdar et al. [34].

From this work has evolved a growing body of literature focused on the impacts of voltage fluctuations caused by transient cloud cover on the grid and on its voltage regulation devices as well as methods of predictive modeling, changes to operational settings, or the integration of energy storage as a means to mitigate these impacts ([35, 36]; New Power [37-40]).

One of the things that is striking about this wealth of solar energy literature is the relative dearth of PV energy research in the northeastern U.S. and the lack of detailed assessments of voltage screening methodologies currently in use. Smith and Armstead [41] used the short-term behavior of the solar resource in central New York to establish on-the-ground observations of ramp rates and how the correlation coefficient between ramps at different sites scale with distance. We expand on these results and draw connections between that data and data from NREL's Measurement and Instrumentation Data Centers in the eastern U.S. to confirm that those observations are representative. Finally, we combine all of our sources of data to develop support for a simplified screening methodology to study the impact of solar PV installations on the northeastern grid, both alone and in aggregate with other solar facilities on the same feeder or substation.

This work is inspired by the work of Smith and Armstead [41] where a set of residential and light commercial solar PV systems in Central New York were monitored using customer-sited monitoring equipment sampled at a rate of 5 minutes. This data was used to determine the frequency and magnitude of solar ramp rates and the correlation in ramp rates between sites. They validated the monitoring portal's data both by comparing the peak power realized at each site to the rated power of the system and by comparing three years of production data to that predicted by PVWatts.

In the same region, they reported on the results of solar irradiance measurements from a pair of pyranometers sampled at one-second intervals. They selected the sensors' separation distance to make it typical for solar panels in a single utility scale (rated capacity on the order of megawatts) array and determined the smoothing of solar irradiance ramps that would be expected for larger systems, extended the model of Hoff and Perez [42] and showed the consistency of this model with real-world data [41].

We expand on these studies to include the use of multiyear solar irradiance data collected at the Measurement and Instrumentation Data Center (MIDC) sensors maintained at the Oak Ridge National Laboratory in Tennessee as well as those at Elizabeth City State University in North Carolina and Bluefield College in West Virginia. This data allows consideration of inter- and intrayear variations in the ramp rates. The goal of this work is twofold. First is to present a screening threshold of $5 \%$ for the voltage fluctuation modeled by a full on-to-off transition of a solar system. Second is to present a simple model in situations of high densities of solar facilities to assess the impact of an additional solar facility. The model sets the level of impact for systems already existing on a single feeder based on their separation. In doing so, it allows a single screening threshold for protecting against unacceptable impacts of solar variability on the voltage of the distribution grid. Through the use of our measured ramp rates, we establish that the model is conservative.

\section{Experimental Setup}

In the present work, we will use a number of sources of data as follows:

(1) NREL's MIDC sensors maintained at the Oak Ridge National Laboratory (ORNL) in Tennessee [43]. This system records global horizontal irradiance using a LICOR LI-200 pyranometer mounted on a rotating shadowband radiometer (RSR) from Irradiance Inc. Data with a resolution of one minute is available from September 12, 2007, to present. For our analysis, we consider nine full years of data from January 1, 2008, to December 31, 2016. We label data from this source during this interval the Tennessee Global Horizontal Irradiance dataset (TGHI dataset) (see Figure 1)

(2) The MIDC sensors maintained at Elizabeth City State University in North Carolina [44]. This system records global horizontal irradiance using Eppley Laboratory, Inc. model precision spectral pyranometers. Data with a resolution of five minutes is available from September 25, 1985, to November 19, 2014. For our analysis, we considered only the full years of data between 2008 and 2016 for consistency with data from ORNL. We label data from this source during this interval the North Carolina Global Horizontal Irradiance dataset (NCGHI) (see Figure 1)

(3) The MIDC sensors maintained at Bluefield College in West Virginia [45]. This system also records global horizontal irradiance using Eppley Laboratory, Inc. model precision spectral pyranometers. Data with a resolution of five minutes is available from November 6, 1985, to April 13, 2015, at Bluefield College. For our analysis, we again considered only the full years of data from these sites between 2008 and 2016 for consistency with data from ORNL. We label data from this source during this interval the West Virginia Global Horizontal Irradiance dataset (WVGHI) (see Figure 1)

(4) A pair of pyranometers situated in Ulysses, NY, with a separation of $\sim 170 \mathrm{~m}$ (see Figure 2 and [41]). This system used S-LIB-M003 solar irradiance sensors. 


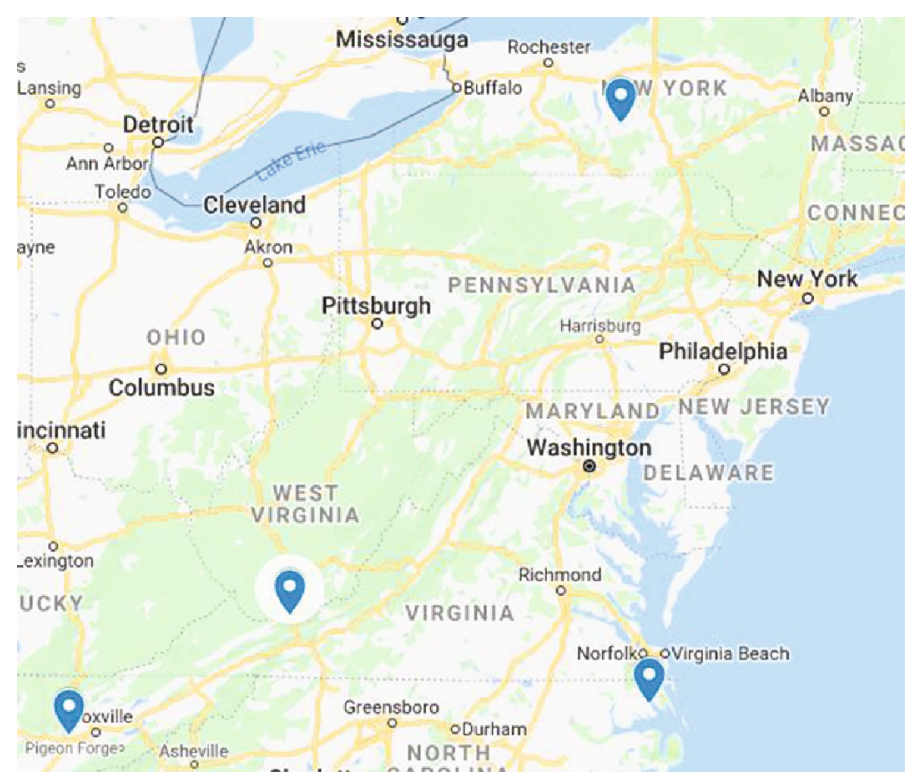

FIGURE 1: Map of four pyranometer locations for the TGHI dataset, bottom left; NCGHI dataset, bottom right; WVGHI dataset, bottom center; and NYI dataset, top (Google map).

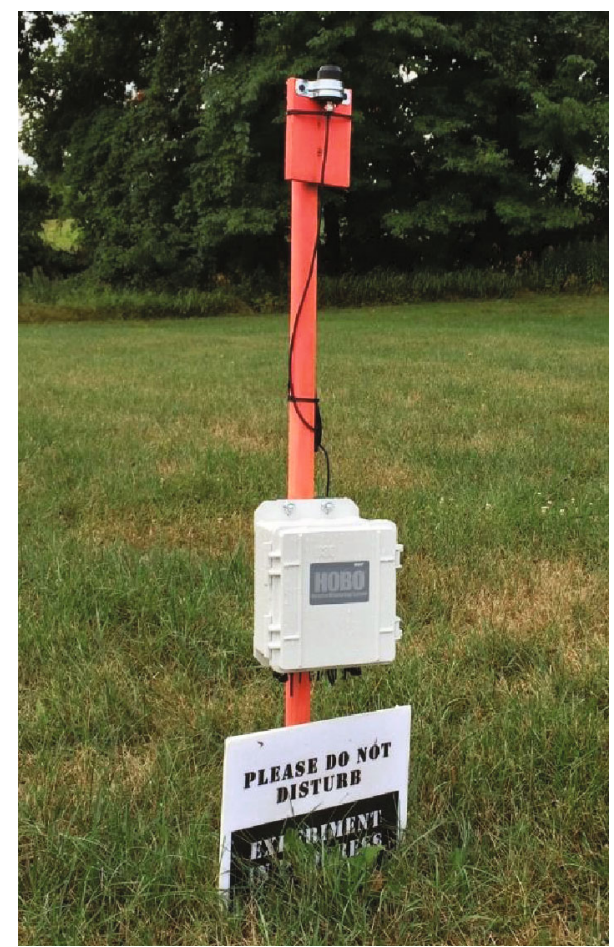

FIGURE 2: One of two solar irradiance sensors deployed for short timescale study.

Data with a resolution of one second is available from August 1 to 8, 2016. We label data from this source during this interval the New York irradiance dataset (NYI) (see Figure 1)

(5) Six pole-mounted residential and small commercial solar PV systems (see Figure 3 and [41]). These use commercial-grade energy monitoring equipment marketed as part of SunPower and reported via internet connection. The two full years of reliable data from these sites between 2008 and 2016 are 2013 and 2015. We label data from this source during these intervals the New York PV System dataset (NYPVS)

While the MIDC stations in Tennessee, North Carolina and West Virginia are far removed from the solar systems in Central New York (see Figure 1), together they provide a baseline for understanding long-term seasonal variations in solar irradiance fluctuations in the Eastern U.S. as well as valuable comparisons to the data from the irradiance sensors and customer-sited monitoring equipment at the New York PV systems. As can be seen in Table 1, all data is expected to have an uncertainty of at least $2.5 \%$ with the greatest uncertainty in the NYPVS data which may be as high as $8 \%$.

\section{Frequency and Magnitude of Solar System Ramp Rates from TGHI Dataset}

We now consider the frequency and scale of ramp rates in solar irradiance in the TGHI dataset.

3.1. Interannual and Seasonal Variations in Ramp Rates. To consider the impact of averaging time as well as seasonal and interannual differences on the magnitude, frequency, and distribution of solar ramp rates in the TGHI dataset, we calculated the irradiance ramp rates for each interval between 8 am and $8 \mathrm{pm}$ as shown in the following equation:

$$
I_{\mathrm{rr}}=\frac{I_{n+1}-I_{n}}{I_{\mathrm{STC}}},
$$

where $I_{n}$ is the $n$th global horizontal irradiance interval average (we primarily consider intervals one or five minutes) and $I_{\mathrm{STC}}$ is taken to be $1,000 \mathrm{~W} / \mathrm{m}^{2}$. We have chosen this value so 


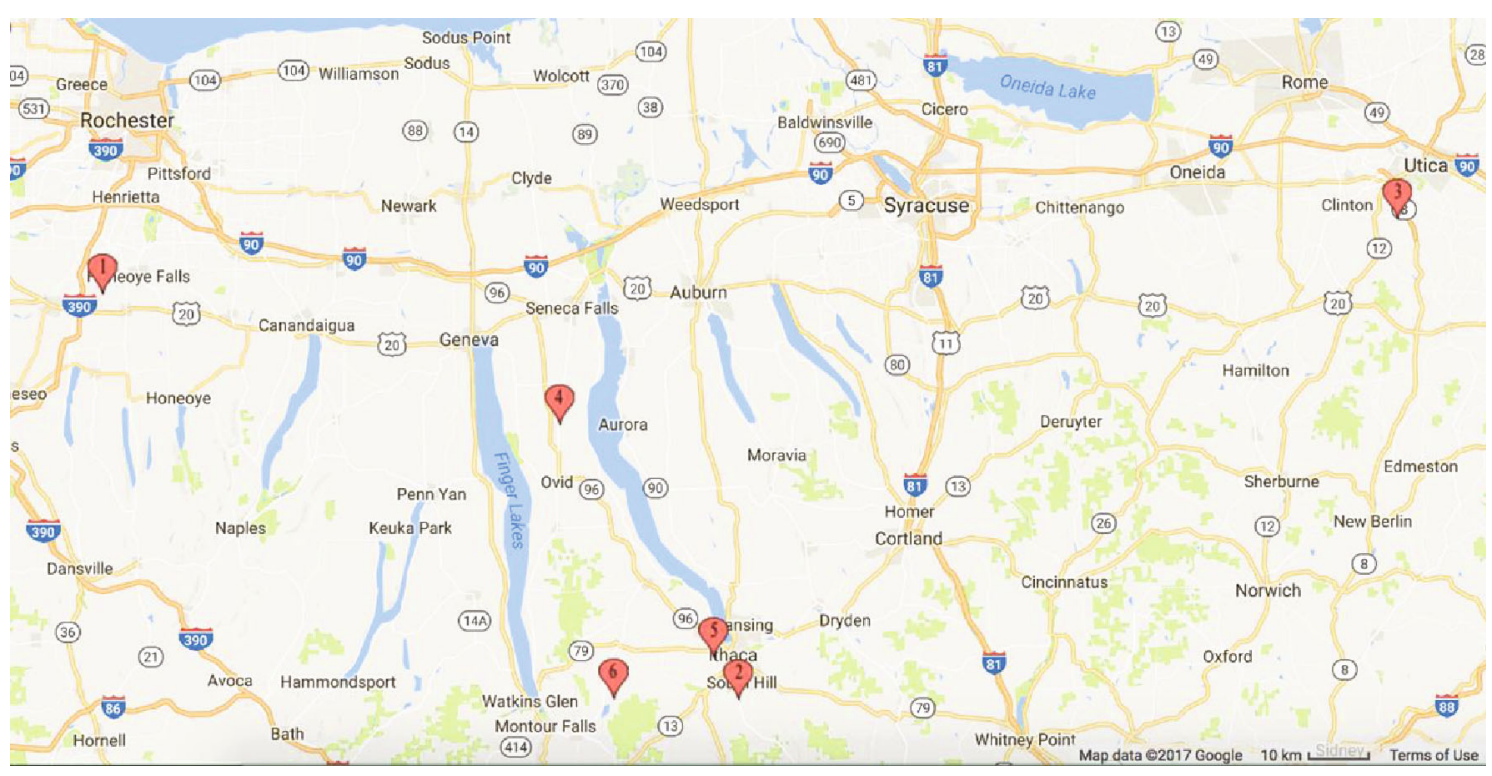

FIGURE 3: Location of six pole-mounted solar PV systems.

TABLE 1: Detectors used in for each of our 5 data sources.

\begin{tabular}{|c|c|c|}
\hline Dataset & Detector & Accuracy \\
\hline TGHI & LICOR LI-200 pyranometer & Estimated uncertainty $\pm 3 \%$ from LICOR data sheet \\
\hline NCGHI & $\begin{array}{l}\text { Eppley Laboratory, Inc. model precision } \\
\text { spectral pyranometers }\end{array}$ & $+3 \%-4 \%$ estimated from calibration documentation \\
\hline WVGHI & $\begin{array}{l}\text { Eppley Laboratory, Inc. model precision } \\
\text { spectral pyranometers }\end{array}$ & $\begin{array}{c}\text { At least } \pm 2.5 \% \text { (linearity }+ \text { temperature dependence }+ \text { cosine response } \\
\text { from spec sheet })\end{array}$ \\
\hline NYI & Onset silicon pyranometer model S-LIB-M003 & $\pm 5 \%$ from onset data sheet \\
\hline NYPVS & $\begin{array}{l}\text { Commercial SunPower monitoring } \\
\text { equipment of PV power installations }\end{array}$ & $\begin{array}{l} \pm 8 \% \text { compared to DC rated capacity and } \pm 5 \% \text { calibrated against NYI data } \\
\text { (actual calibration was } \pm 4 \% \text { but is limited by onset calibration) }\end{array}$ \\
\hline
\end{tabular}

that the normalized irradiance measurements have the same overall meaning as the normalized power output ratio used in Smith and Armstead [41] given that the rated power of a solar system is determined under standard test conditions with an irradiance of $1,000 \mathrm{~W} / \mathrm{m}^{2}$.

As expected and reported in Table 2, at both the one- and five-minute timescales, the frequency of large fluctuations $\left(I_{\mathrm{rr}}>0.3\right)$ in solar output was greater over the three high solar resource months of May, June, and July than over the entire year. The same relationship was also true for the RMS ramp rates. In addition, the one-minute frequency and magnitude of fluctuations were uniformly smaller than those at the five-minute resolution for both the annual average and the three spring/summer months (see Table 2 and Figure 4).

Finally, for the two years for which we had data from the New York solar systems (2013 and 2015), we find that those years are comparable to the TGHI dataset average and that they were, in fact, the two years with the highest variability in the solar resource during the three spring/summer months.

While the TGHI data was collected $\sim 1000 \mathrm{~km}$ from the NYPVS data, it provides a valuable point of comparison between the Tennessee and New York observations. Specifically, the broad consistency of the TGHI dataset with the NYPVS data provides confidence that the results from the
TABLE 2: Frequency and magnitude of ramp rates in solar irradiance between 8 am and $8 \mathrm{pm}$ over the entire years as compared to three spring/summer months illustrating the expected trend of larger variability during the higher solar resource months.

\begin{tabular}{lcc}
\hline & $\begin{array}{c}\text { Annual } \\
\text { average }(1)\end{array}$ & May to July (1) \\
\hline Percent of $I_{\mathrm{rr}}>0.3$ (1 minute) & $1.2 \pm 0.1 \%$ & $2.5 \pm 0.2 \%$ \\
Percent of $I_{\mathrm{rr}}>0.3$ (5 minute) & $1.9 \pm 0.1 \%$ & $3.9 \pm 0.3 \%$ \\
$\left(I_{\mathrm{rr}}\right)_{\mathrm{RMS}}(1$ minute) & $6.2 \pm 0.2 \%$ & $8.6 \pm 0.4 \%$ \\
$\left(I_{\mathrm{rr}}\right)_{\mathrm{RMS}}(5$ minute) & $8.1 \pm 0.2 \%$ & $11.3 \pm 0.4 \%$ \\
\hline
\end{tabular}

spring/summer of 2013 and 2015 are accurate in spite of the use of commercial-grade data collection equipment and are not likely to underestimate the actual long-term annual average for the distribution of fluctuations. For example, the NYPVS dataset matches closely the corresponding May to July data from the TGHI dataset and both show higher rates of large ramps as compared to the annual average (see Figure 5).

3.2. Short-Term Periods of High Variability Related to Measurements of Flicker. In addition to calculating frequency and magnitude of ramp rates, we explore the impact of these 


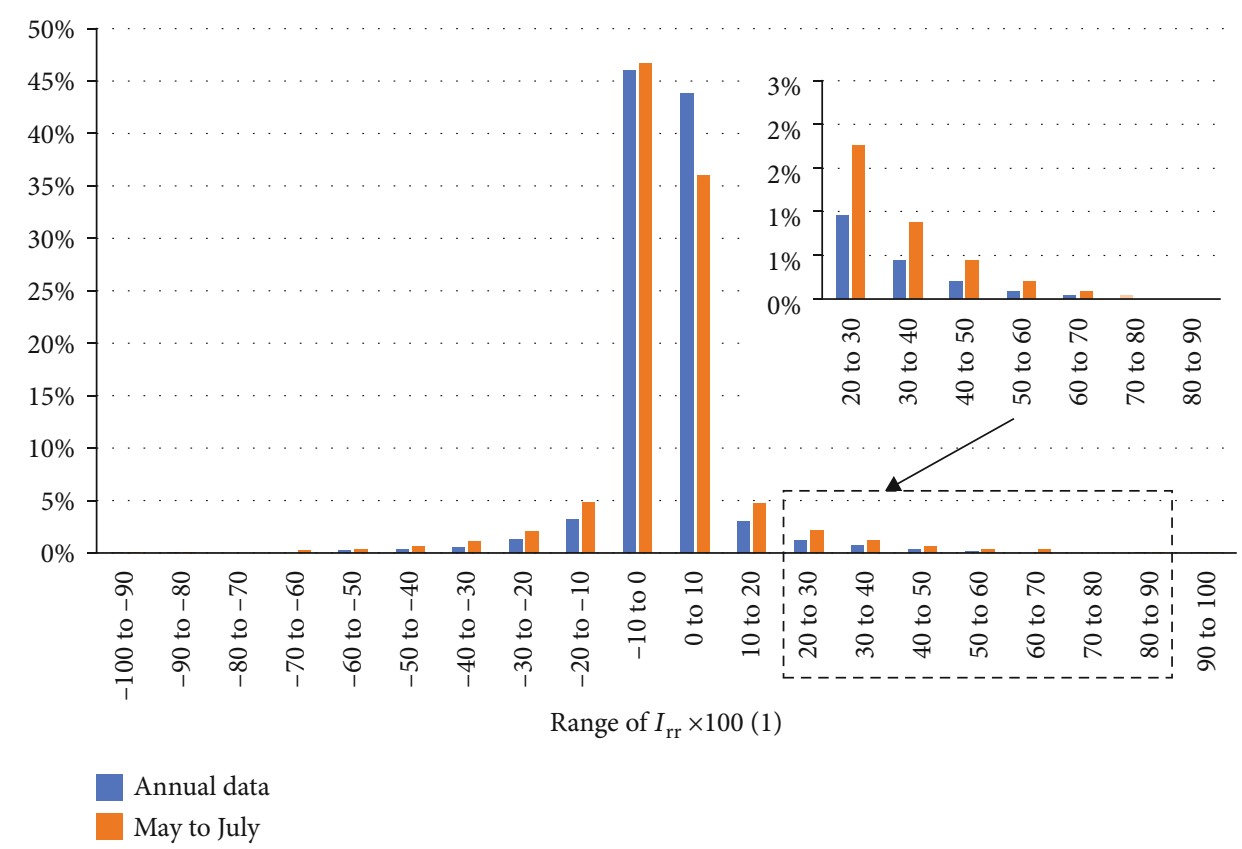

FIgURE 4: Histogram of the frequency of irradiance ramp rates in various ranges as measured across the entire year as compared to the interval May-July. The inset shows the higher incidence of larger ramp rates in the spring/summer months as expected.

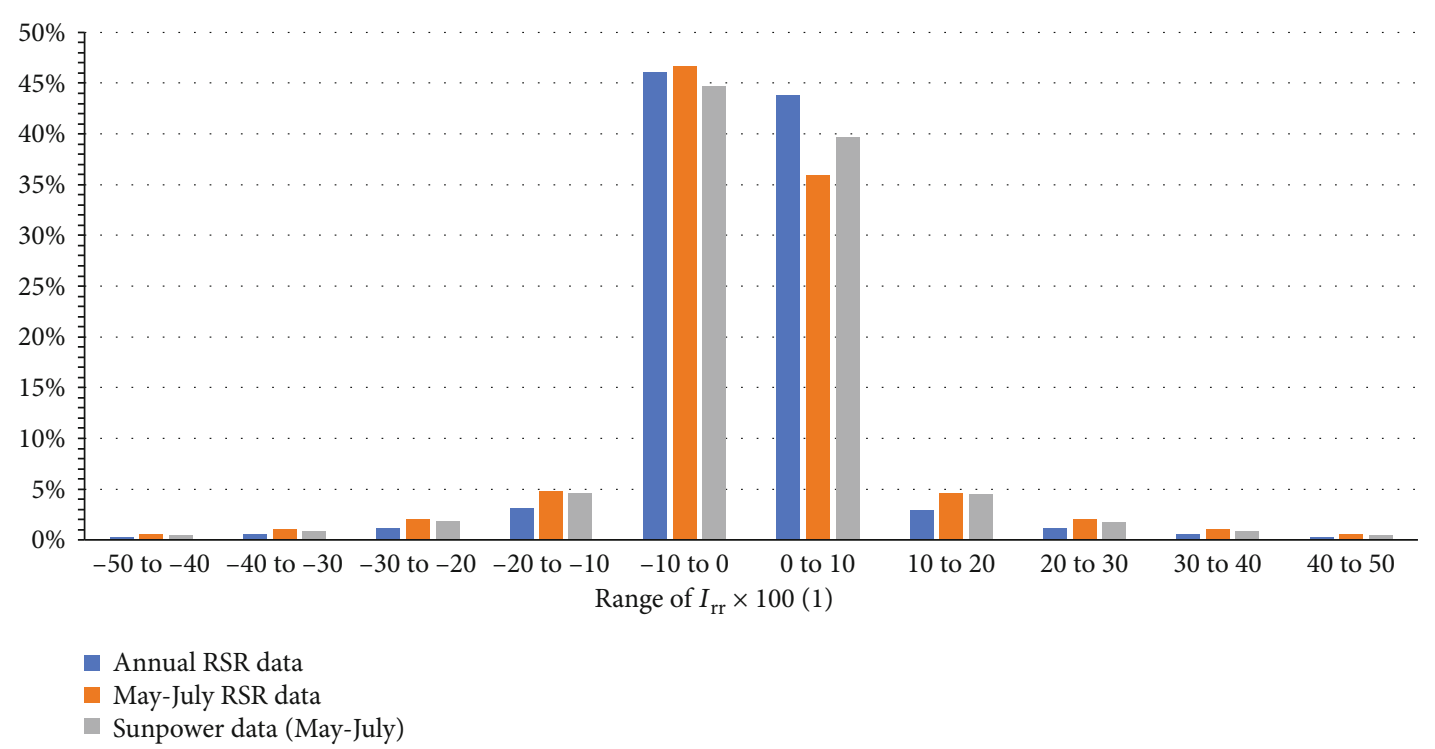

FIGURE 5: Histogram of the frequency of irradiance ramp rates in various ranges as measured across the entire year at the Oak Ridge RSR as compared to the interval May-July for both the Oak Ridge Tennessee site and the NYPVS SunPower systems. Only ramp rates up to $\pm 50 \%$ are shown as this captures more than $99 \%$ of all data in each of the three datasets.

fluctuations in irradiance. The most accurate measurement of annoyance due to transient changes in grid voltage (e.g., due to solar PV-induced fluctuations) uses a short-term and long-term flicker annoyance probabilities that are calculated on 10-minute and two-hour windows, respectively (see Section 4.1 for more details).

To determine whether our focus on the frequency and scale of ramps in solar output over the time frame of months to years may be missing shorter periods of high variability that would dominate the system's impact on the grid, we calculated the RMS fluctuation across all 10-minute windows in the TGHI dataset. The maximum RMS fluctuation encountered in each year occurred between April 21st and July 25th and averaged $47 \pm 2 \%$.

The shape of the variations in solar output can influence their impact on the grid. Figure 6 shows the normalized irradiance in the TGHI dataset for the 10-minute windows with the greatest RMS fluctuation. 


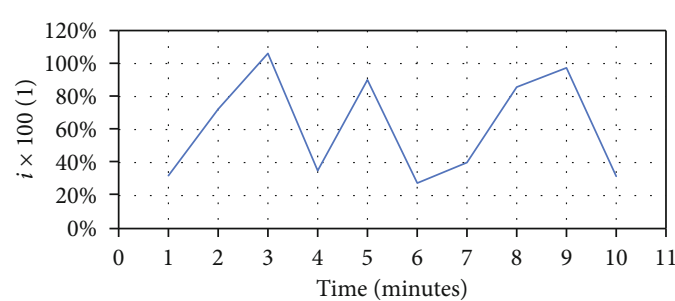

(a)

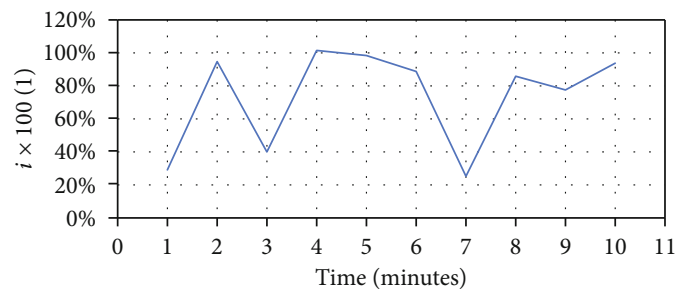

(c)

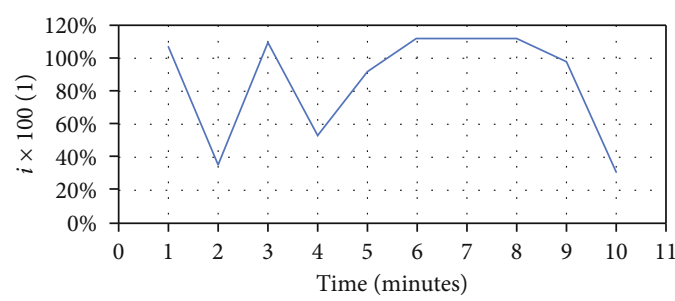

(e)

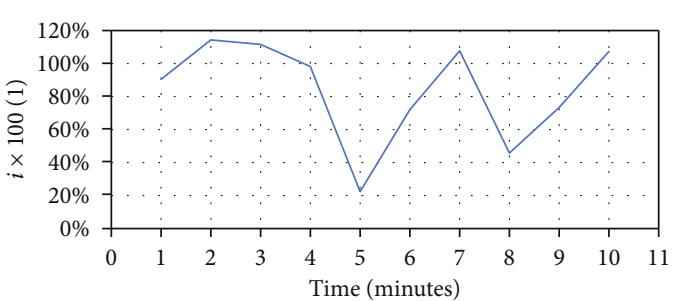

(b)

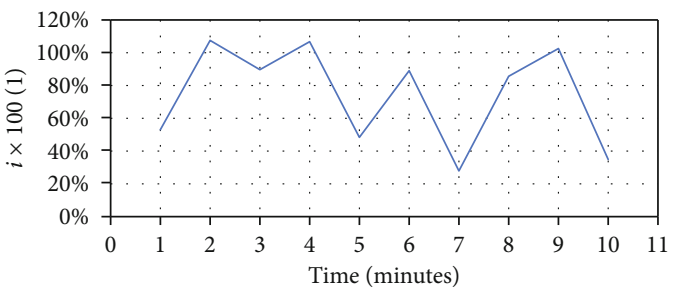

(d)

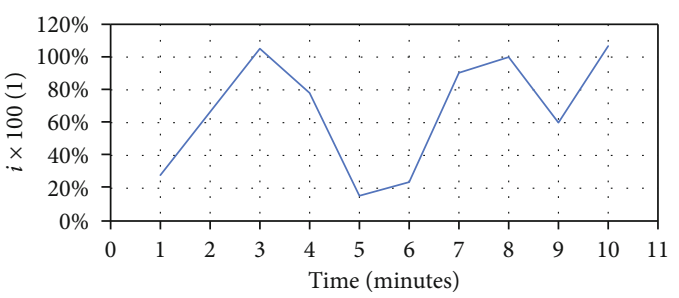

(f)

FIGURE 6: Normalized solar irradiance data, $i_{n}=I_{n} / I_{\mathrm{STC}}$, from the TGHI dataset over the 10 minutes per year with the highest RMS ramp rates. As one would expect for ramps caused by passing clouds, the changes in solar output can vary significantly from year to year. (a) 2016 (the year with the highest overall variability in the data), (b) 2014, (c) 2013, (d) 2012, (e) 2011, and (f) 2009. The three years not shown had similar waveforms to one of the above with 2008 comparable in shape to 2016, and both 2014 and 2015 are similar to 2009.

\section{Derivation of Flicker Screening Threshold from Measurements of Solar Ramp Rates}

The frequency and magnitude of changes in the power output along with the maximum 10-minute RMS irradiance fluctuations can be combined to support a simple and internally consistent screening threshold amenable for use in determining when a detailed study of a proposed PV system is required and, just as importantly, when it is not.

Based on both the old and new methodologies for determining the impact of transient changes in voltage resulting from ramps in solar output, we propose here a voltage flicker screen that is equivalent to a limit of $5 \%$ on the change in system voltage when modeling a transition of the solar system from full on (i.e., $100 \%$ of rated power) to full off (i.e., $0 \%$ of rated power). A similar screen has recently been proposed in draft recommendations from the Electric Power Research Institute (EPRI) for adoption in New York State [46], and the present work provides robust support for its adoption.

4.1. Review of Flicker: Limits and Methodologies. Variations in line voltage with time, commonly called flicker, can often be among the most important factors determining the hosting capacity of a distribution feeder $[4,8,9]$. Thus, in the context of utility review, many states including California,
Massachusetts, and New York along with the Federal Energy Regulatory Commission (FERC) make use of similar screening processes designed to determine whether or not a full engineering study is warranted [47-50].

Many of these jurisdictions require as part of these screens the application of the flicker methodology detailed in IEEE 1453 or a similar utility practice. The principal method in IEEE 1453 involves the use of a "flickermeter" designed to quantify the perception of flicker by filtering the voltage profile to mimic the response and sensitivity of the eye and brain to flickering lightbulbs at different timescales [51]. The results of the flickermeter reading are the short-term and long-term perceptibility index called $P_{\text {st }}$ and $P_{\mathrm{lt}}$. These indices are normalized so that a value of one corresponds to conditions where half of the observers would notice that a light is flickering and find it irritating. Finally, the standard limits how much of the time the measured flicker can exceed the regulation threshold (e.g., on medium voltage systems $(1 \mathrm{kV}-35 \mathrm{kV})$, the allowable fraction of time the circuit monitored can have significant flicker (thresholds of $P_{\mathrm{st}}=0.9$ and $P_{\mathrm{lt}}=0.7$ ) is than $1 \%$ (minimum assessment period of one week) [51]).

4.2. Derivation of a $\triangle V / V$ Screen from IEEE 1453 and 10Minute RMS Ramp Rates. While the use of the flickermeter in IEEE 1453 is straightforward retrospectively as a means 
to test the impact of a system once it is operational, the use of such techniques prospectively is complex and requires data that is not always available. In addition, the need for sophisticated modeling tools makes this technique difficult to use in its fullest manner at the study level. As such, a simple screening analysis is generally applied first by comparing the voltage change resulting from turning the solar PV system from full on to full off in a utility's distribution models and comparing the results against a given threshold [52, 53].

Such transitions from $100 \%$ to $0 \%$ capacity are not typical and will be very unlikely to repeatedly occur in the real world. For example, we found no instances of fluctuations in normalized irradiance greater than $90 \%$ in the TGHI, NCGHI, and WVGHI datasets. At a resolution of one minute, there were just 10 total instances of fluctuations between $80 \%$ and $90 \%$ out of more than 2.37 million data points in the TGHI dataset. At a resolution of five minutes, there were only 10 total instances of fluctuations between $80 \%$ and $90 \%$ in 267,360 data points in the NCGHI dataset and just seven instances in 278,464 data points in the WVGHI dataset. As such, if this type of simple screen is failed (full on to full off), a more detailed time series analysis using realistic insolation data can be conducted as part of a full system impact assessment.

According to IEEE $1435 P_{\text {st }}=1$ for a rectangular voltage fluctuation $\Delta V / V=3.166 \%$ at a timescale of one change per minute [51]. The planning level for medium voltage distribution systems is a $P_{\text {st }}=0.9$. This suggests a limit of $\Delta V / V=$ $3.166 \% * 0.9=2.849 \%$. In the interest of having a conservative threshold, we instead choose a limit of $\Delta V / V=3.166 \%$ $\times 0.8=2.533 \%$ at the point of common coupling.

Based on our calculations of $\left(I_{\mathrm{rr}}\right)_{\mathrm{RMS}}$ for all 10-minute windows in the TGHI dataset, the highest value ever recorded was $49.4 \%$ occurring on April 28, 2016. While the planning levels for flicker are intended not to be exceeded for more than $1 \%$ of the time, we will use this highest recorded RMS ramp rate (a worst case scenario) to support a conservative screening limit. Using these values results in a screening threshold of 5\% (i.e., 2.533\%/0.494) or below for acceptable voltage fluctuation that results from modeling a simple-to-specify but never-observed full-on-to-off transition.

We note that the voltage variations in Figure 6 appear more triangular or rounded than square at this resolution. IEEE 1453 includes the application of a shape factor to modify the limit for nonsquare wave changes that would increase our allowed threshold (see Figure C.2 in IEEE [51]). To determine if this modifier is appropriate to use, we consider the impact of our one-minute measurement rate on our conclusions. To support our argument that a one-minute time resolution is fine enough, we revisit the relevant results and data from Smith and Armstead [41]. They observed that the spatial averaging that occurs over megawatt scale systems causes a rapid decrease in the variability of solar ramp rates below one minute. In addition, solar irradiance data collected at one-second resolution over nine days (a reasonable assessment period under IEEE 1453) provides further confidence that considerations of shorter timescales would be unlikely to result in more stringent limits.
Figure 7 shows the solar irradiance profiles from the NYI dataset during the 10-minute window of the highest RMS fluctuation we measured. As can be seen, the changes in system output become squarer at shorter timescales (contradicting use of a shape factor correction) and the variation in output from one measurement to the next generally becomes smaller.

From this data, we computed the RMS ramp rates over all 10-minute windows at various timescales below one minute. As shown in Figure 8, the proportional reduction in RMS ramp rates as compared to the value at one minute closely tracks the decreasing voltage thresholds in IEEE 1453 for $P_{\mathrm{st}}=1$ providing confidence that the limits we derived using the one-minute TGHI dataset would not likely be violated over shorter periods. The power smoothing due to geographic dispersion makes the 5\% screening threshold even more conservative as we derived our results for individual irradiance sensors.

4.3. Support for $\Delta V / V$ Screening Threshold from Superseded IEEE 519 Flicker Curves. In the previous section, we derived a screening threshold of $5 \%$ for the voltage fluctuation modeled by a full-on-to-off transition of a solar system based on the maximum RMS ramp rate over any 10-minute window of data from the TGHI dataset and supported by the NYI dataset. Additional lines of support for this proposed threshold can be derived from the now-superseded flicker curves in IEEE 519.

While these flicker curves have been replaced by the newer IEEE 1453 methodology, they are still in use by utilities today. For comparison to the limit derived in the previous section, we will use the so-called borderline of irritation, below which flicker is generally not considered aggravating. This is consistent with practice in high penetration states like California and the current version of IEEE 1547 which sets standards for the interconnection of distributed generation and was adopted before the change to IEEE 519 removing the flicker curves $[47,54,55]$. As in the previous section, we can then convert the voltage fluctuation limits from the flicker curves to an effective screening threshold for use in simplified analyses where a full-on-to-off transition of the solar system is modeled.

For the NYPVS dataset, we calculated the 99th percentile for fluctuations between 8 am and $8 \mathrm{pm}$ as well as over the narrower $10 \mathrm{am}$ to $4 \mathrm{pm}$ time frame. To be conservative, we combined all of the systems from the smallest $(2.88 \mathrm{~kW})$ to the largest $(37.3 \mathrm{~kW})$ despite the expectation that larger systems will have fewer large fluctuations and we modeled our data to be equivalent to that for systems with a DC to AC ratio of 1.3 to 1 common in larger systems. With this ratio, the 99th percentile ramp rate between 8 am and 8 pm was $50 \%$ and that from 10 am to $4 \mathrm{pm}$ was $60 \%$. The five-minute borderline of irritation limit from the now-superseded IEEE 519 flicker curves was 3\% [51, 56]. This yields voltage limits of $6 \%$ (i.e., 3\%/.5) and 5\% (i.e., $3 \% / 0.6)$, respectively. Keeping our more conservative result, this voltage limit would again translate into a flicker screening threshold of 5\% (i.e., 3\%/0.6) when applied to a full-onto-off transition. 


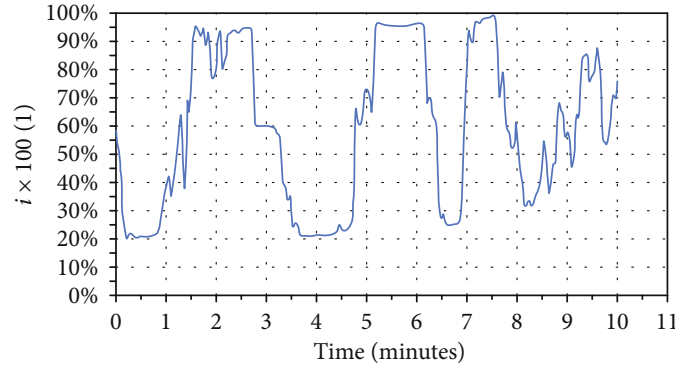

(a)

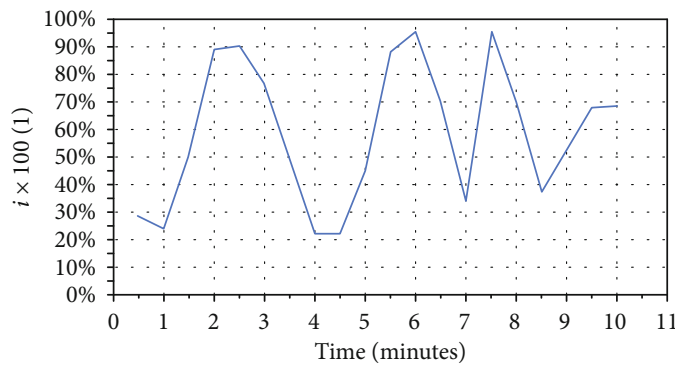

(c)

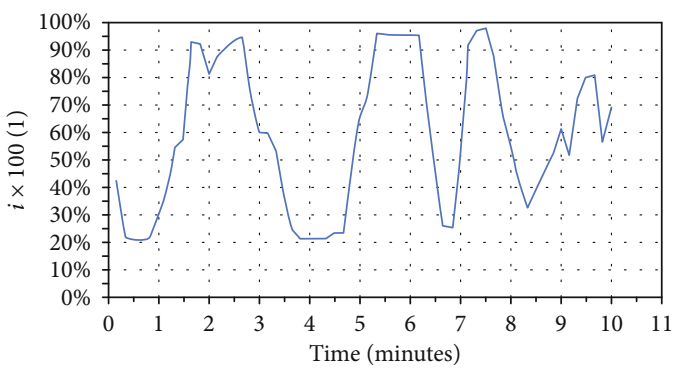

(b)

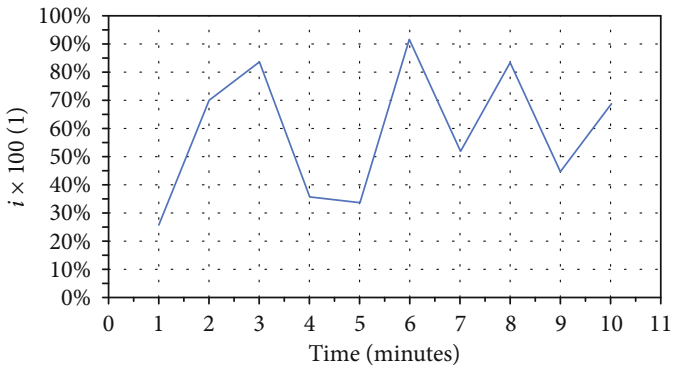

(d)

FIGURE 7: Normalized irradiance measurements, $i_{n}=I_{n} / I_{\mathrm{STC}}$ from the NYI observations for different averaging times: (a) one second, (b) 10 seconds, (c) 30 seconds, and (d) 60 seconds. The graphs correspond to the 10-minute window with the highest RMS ramp rate encountered in the NYI dataset which occurred on August 4, 2016.

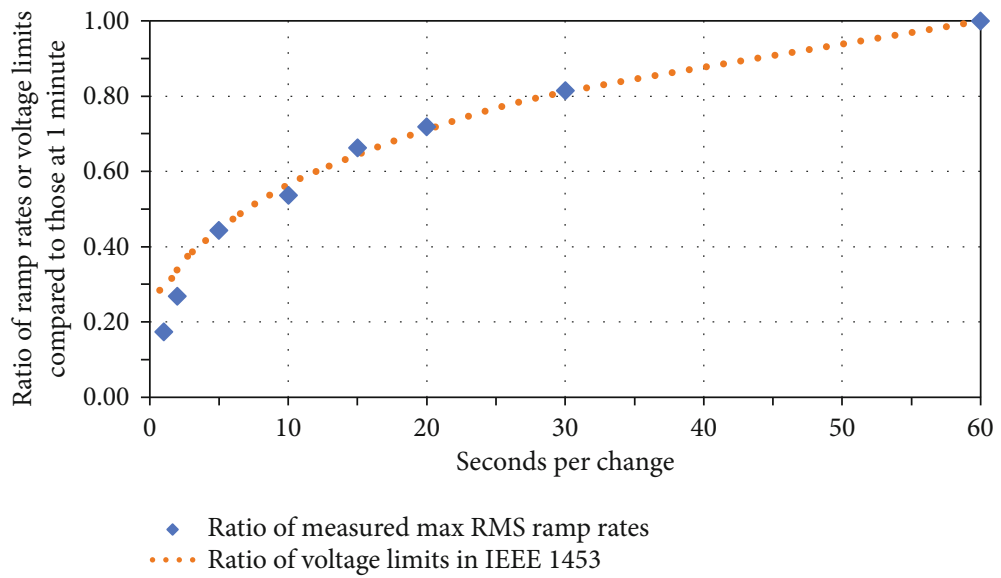

Figure 8: Ratio of the maximum RMS ramp rate calculated over all 10-minute windows for each irradiance sensor as compared to the maximum RMS ramp rate at one minute plotted against the ratio of voltage thresholds in IEEE 1453 for $P_{\text {st }}=1$ as compared to the limit at a resolution of one change per minute.

Similar results are found for the TGHI dataset as well. At the resolution of one minute, we found that from 8 am to 8 pm, $99.45 \pm 0.04 \%$ of all fluctuations in global horizontal irradiance were less than $40 \%$. Restricting the window to 10 am to $4 \mathrm{pm}$, we found that $98.92 \pm 0.08 \%$ of all fluctuations in irradiance fell within the range of $40 \%$. As these are single point measurements of irradiance and thus already likely to overestimate the actual fluctuations in power output expected from larger solar arrays, we did not include the impacts of a higher $\mathrm{DC}$ to $\mathrm{AC}$ ratio. At one voltage change per minute, the borderline of irritation yields a voltage fluctuation limit of $2 \%$. Using the 99th percentile for such variations between 10 am and $4 \mathrm{pm}$, this limit again translates to a 5\% flicker screening threshold (i.e., 2\%/0.4) when applied to a full-on-to-off transition.

For the longer five-minute timescale, $99.67 \pm 0.04 \%$ of the fluctuations in the TGHI dataset between 8 am and 8 pm were less than $50 \%$ while $99.34 \pm 0.08 \%$ of fluctuations between 10 am and $4 \mathrm{pm}$ were less than $50 \%$. As noted above, the fiveminute borderline of irritation limit was approximately $3 \%$ which yields $6 \%$ (i.e., $3 \% / 0.5$ ) and would be equivalent to a flicker screening threshold in excess of $5 \%$ for this timescale.

Finally, to ensure that our results are, in fact, adequately conservative for use in screening analyses, we identified the 99th percentile ramp rates at a resolution of five minutes for the NCGHI and WVGHI datasets. We found a 99th 


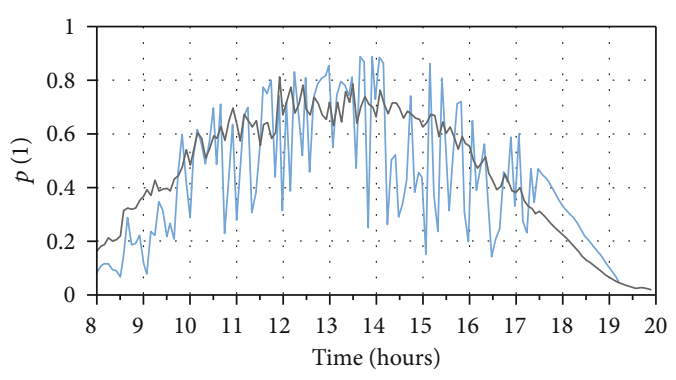

— Individual site - Avg of all sites

(a)

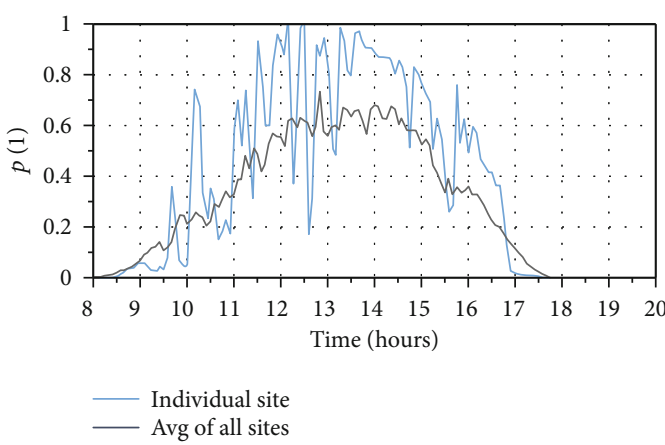

(c)

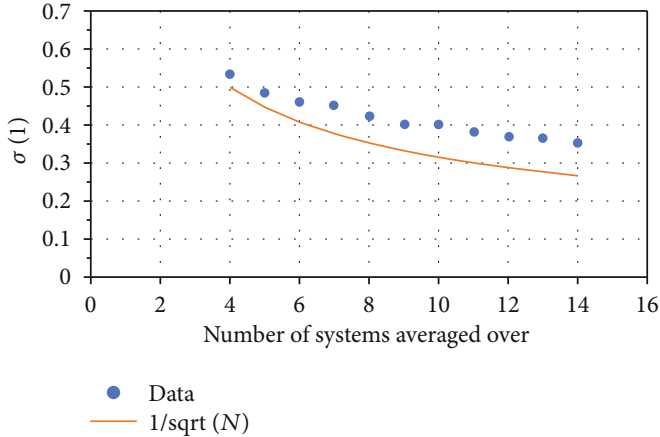

(b)

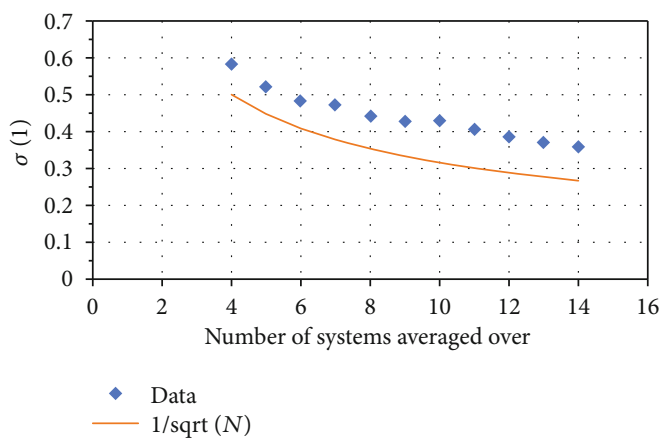

(d)

FIGURE 9: Smoothing of solar output, $p_{n}=P_{n} / P_{s}$, due to geographic dispersion of systems on days of high solar variability in spring/summer and fall/winter months: (a) normalized production of a single system (blue) and the average of 14 systems (gray) on July 26, 2016; (b) reduction in the variance of solar ramp rates, $\sigma=\sigma_{\mathrm{avg}} / \sigma_{1, N}$, in spring/summer as a function of the number of systems over which averaging takes place; (c) normalized production of a single system and the average of 14 systems on November 4, 2016; (d) reduction in the variance of solar ramp rates in fall/winter as a function of the number of systems averaged over.

percentile ramp rate in the NCGHI dataset of $38.3 \%$ for 8 am to $8 \mathrm{pm}$ and $43.3 \%$ between 10 am and $4 \mathrm{pm}$. For the WVGHI dataset, we found a 99th percentile ramp rate of $42.6 \%$ for 8 am to $8 \mathrm{pm}$ and $49.0 \%$ for 10 am to $4 \mathrm{pm}$. Both of these results are smaller than the $50 \%$ ramp rate we found as the 99th percentile ramp rate for the TGHI dataset providing confidence that our use of that data is suitably conservative.

The fact that the older IEEE 519 methodology results in similar conclusions for our proposed screening threshold to that derived in Section 4.2 is noteworthy, given the acknowledged conservatism in this approach. As noted by Broderick et al. [52],

"The disadvantage of using the older IEEE 519 flicker curves for evaluating the voltage variation caused by PV is twofold. First, the flicker curve requires knowledge of not only the percent voltage dip caused by variation in PV plant output but also the frequency of the voltage dip. The frequency can be very difficult to quantify for cloud patterns that are not consistent. The second problem is the design of the flicker curve which was developed to address fast voltage changes such as motor starts and not the slowly changing voltage variation seen with PV. These problems with the IEEE 519 flicker curves often lead to an unnecessarily conservative approach for determining PV induced flicker impact."

While our observations on solar ramp rates help address the first of these issues, the second disadvantage remains.

\section{Correlation of Ramp Rates at Longer Length Scales and Impact of Aggregated DG}

The above section describes the derivation of a flicker screening threshold based on measurements at individual sites. As higher penetrations of solar PV systems are reached, it becomes increasingly necessary to determine the impact aggregations of multiple systems have on the distribution system.

To incorporate multiple solar systems on a single feeder into our screening analysis, we used the results presented in Smith and Armstead [41] for the correlation of ramp rates between systems at length scales appropriate to rural electric circuits. From these, we developed a simple scaling tool to incorporate geographic diversity and allow the fluctuations from multiple systems to be evaluated.

As detailed in Smith and Armstead [41], the model proposed by Hoff and Perez [42] predicts that the correlation in solar irradiance fluctuations varies exponentially with the separation distance between the systems as shown in the following equation:

$$
\text { Correl }=A \times e^{-l / v t}
$$

This model provides a good fit overall for the irradiance sensors and residential and commercial systems in Central New York [41]. 


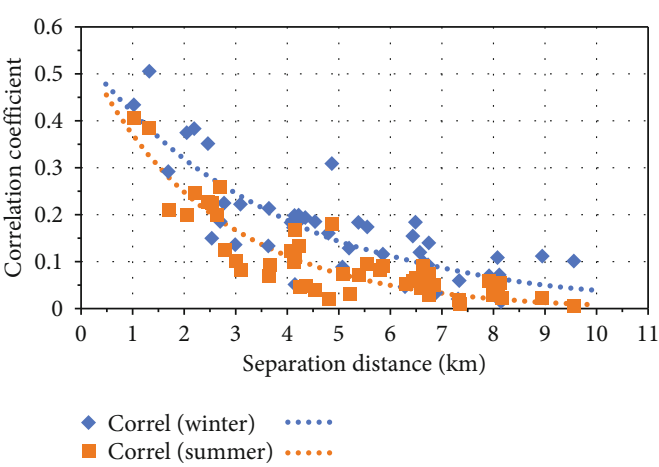

(a)

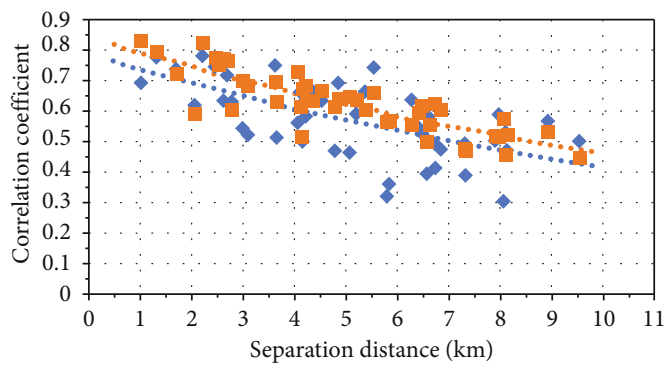

- Data (winter)

Data (summer) ....

(c)

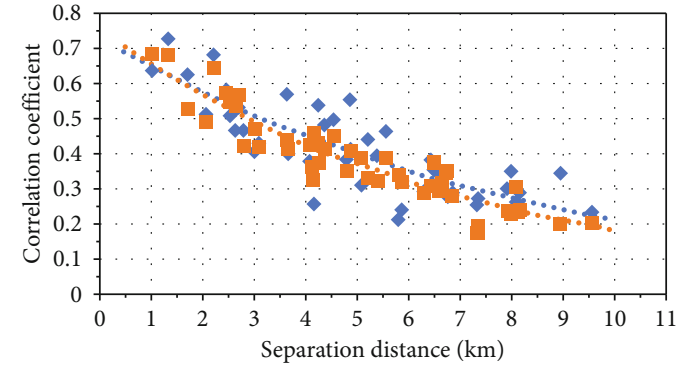

- Data (winter) .....

- Data (summer) .....

(b)

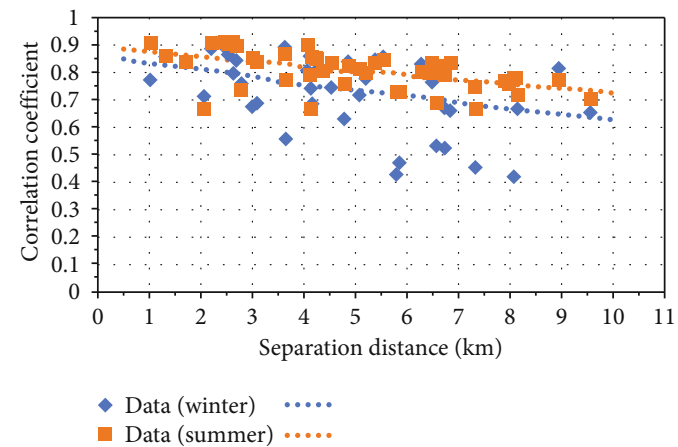

(d)

FIGURE 10: Variation in correlation coefficient with distance in New York. Reproduced from Smith and Armstead [41]. Graph (a) is relevant to the discussion in this section.

In addition, Hoff and Perez [42] proposed a model for the reduction in variability for sparse and crowded distributions of solar arrays. In their model, averaging small numbers of widely separated systems leads to a reduction in the standard deviation of ramp rates approaching $1 / \sqrt{N}$ while for higher densities of more closely spaced systems, the reduction begins to level out approaching $1 / D$ where $D=l / v t$ is the dispersion factor (i.e., the exponent of Equation (2)). Additional data from Smith and Armstead [41] for existing penetrations of solar PV show reasonable agreement with this expected trend. For example, Figure 9 shows the effect of averaging four to 14 systems within a circle of radius $14 \mathrm{~km}$ centered near Ithaca, NY, on the days from each season with the highest solar variability.

Here, we develop a simple-to-implement model for the standard deviation reductions at even higher densities such as those appropriate to individual panels in a megawattscale solar array.

$$
\text { StdDevReduction }_{2 \mathrm{D}}=\frac{1}{2}\left(1+A \times e^{-l / v t}\right) .
$$

We will apply the model, Equation (3), so that the screening threshold will remain conservative even at very high levels of local PV penetration.

When considering timescales of five minutes and less, Smith and Armstead [41] found that the correlation between power ramp rates at the sites dropped to below 0.5 by a distance of 500 meters (see Figure 10(a)). At this level, the variance reduction from averaging the ramp rates of densely packed systems would be 0.75 . By a separation distance of $2.5 \mathrm{~km}$ (i.e., just over one decay length as found in the data), the correlation between the ramp rates at different sites drops to less than 0.3 in both summer and winter resulting in a variance reduction for densely packed systems of 0.65 .

From these results, we propose the following geographic dispersion coefficients for use in aggregating solar systems in the screening calculations. Making use of the fact that the decay in correlations over these length scales does not show a strong directional dependence, we propose grouping systems into three concentric circles (see Figure 11). In this proposal, all systems within 500 meters of a proposed facility are included in the flicker screening analysis with a transition equal to their full rated power (i.e., all solar PV within this distance would be included in the model as going from fully on to off). For systems between 500 meters and $2.5 \mathrm{~km}$, we propose including them in the two modeled states with a ramp in output equal to $70 \%$ of their rated power (i.e., fully on to $30 \%$ of rated power). Finally, for those beyond a radius of $2.5 \mathrm{~km}$, we propose a ramp equal to $60 \%$ of their rated power.

Including all solar PV on a utility's feeder line, but varying the ramp of the proposed and existing PV systems outputs due to their geographic dispersion, retains both the conservative nature required for a screening analysis while allowing a single screening threshold to be applied in all cases regardless of solar penetration. 


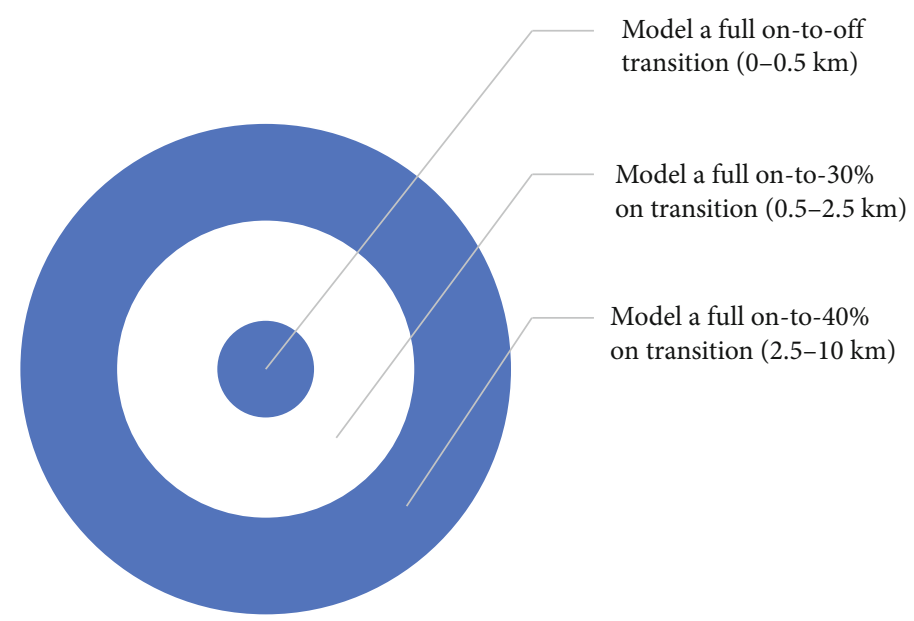

FIGURE 11: Methodology to incorporate aggregations of multiple solar PV systems on a given distribution feeder into the proposed flicker screen. The voltage change on the line that results from this model can then be compared to our flicker screening threshold of $5 \%$.

\section{Concluding Remarks}

In this work, we have made use of our results for frequency and magnitude of ramp rates in solar output to support a new threshold for screening voltage flicker. This screen allows for the aggregation of all systems on a feeder to be taken into account, including the impacts of their geographic dispersion. While our results are derived from the study of residential and small commercial systems and single point measurements of solar irradiance, the results are applicable to larger systems as we have considered the impact of higher $\mathrm{DC}$ to $\mathrm{AC}$ ratios for the solar system data and have shown, consistent with previous works, that megawatt scale arrays have less variability than smaller systems or point measurements of irradiance.

We have demonstrated robust support for a flicker screening threshold equivalent to a $5 \%$ change in voltage resulting from a full-on-to-off transition of a PV facility. This threshold was arrived at by multiple lines of reasoning and can take into account other PV system on the utility's feeder line as detailed in Section 5. While this flicker screening threshold appears similar to that in other standards such as ANSI C84.1 which sets the utilization range for voltage on the distribution system at $\pm 5 \%$ of $120 \mathrm{~V}$ (range A) [57] or IEEE 1547 which sets a $5 \%$ voltage change limit for synchronization [54], there are critical differences which must be commented upon.

For example, concerns have been raised that the application of a $5 \%$ limit for flicker could result in violations of ANSI C84.1 if the nominal system voltage is anything other than $120 \mathrm{~V}$. However, as detailed in Section 4, this screening limit was derived from data on actual RMS and 99th percentile ramp rates that were measured to be in the range of $40 \%$ to $60 \%$ of the rated system power. We translated these various lines of reasoning based on different standards and different timescales into one equivalent limit on a full-on to full-off transition to demonstrate the overall consistency of each methodology and to minimize differences with common utility practice today.

In reality, no ramp over $90 \%$ was observed in two summers of the NYPVS data, in nine years of TGHI data, in seven years of NCGHI data, or in six years of WVGHI data. Ramps at the level of $80 \%$ to $90 \%$ occurred just $0.000422 \%$ of the time at the TGHI site while fluctuations at this scale accounted for less than $0.00312 \%$ of the data available at the NCGHI and WVGHI sites.

Thus, if a proposed PV facility fails this voltage flicker screen, it is unclear if that PV facility would necessarily cross ANSI C84.1 limits given the extreme rarity of large changes in irradiance. Thus, as with all screening analyses, when a screen is failed, the appropriate conclusion is that further study is required, not that a problem necessarily exists in the facility being screened. In this case, if the proposed voltage flicker screening threshold is exceeded, a more detailed time-series analysis should be conducted to more accurately study the impacts of variations in solar irradiance and ensure compliance both with the flicker limits in IEEE 1453 and with the ANSI C84.1 voltage limits.

\section{Abbreviations}

ANSI:

ANSI C84.1:

Correl:

EPRI:

IEEE:

IEEE 1453:

IEEE 1547:

American National Standards Institute ANSI Electric Power Systems Voltage Ratings $(60 \mathrm{~Hz})$ standard

Correlation in solar irradiance

fluctuation

Electric Power Research Institute

Institute of Electrical and Electronics Engineers

IEEE recommended practice for the analysis of fluctuating installations on power systems

IEEE standard for interconnection and interoperability of distributed energy resources with associated electric power systems interfaces

IEEE 519: $\quad$ IEEE recommended practice and requirements for harmonic control in electric power systems

MIDC: $\quad$ Measurement and instrumentation data center 


$\begin{array}{ll}\text { NCGHI: } & \text { North Carolina Global Horizontal } \\ & \text { Irradiance } \\ \text { NYI: } & \text { New York irradiance } \\ \text { NYPVS: } & \text { New York photo voltaic systems } \\ \text { ORNL: } & \text { Oak Ridge National Laboratory } \\ \text { PV: } & \text { Photo voltaic } \\ \text { RSR: } & \text { Rotating shadowband radiometer } \\ \text { StdDevReduction } & \text { 2D }: \\ \text { TGHI: } & \sigma_{\text {avg }} / \sigma_{1, N} \\ & \text { Tennessee Global Horizontal } \\ \text { WVGHI: } & \text { Irradiance } \\ & \text { West Virginia Global Horizontal } \\ & \text { Irradiance. }\end{array}$

\section{Nomenclature}

\section{Roman Symbols}

A: Short-distance/long time correlation between pairs of PV systems

$D$ : Dimensionless dispersion factor

$i$ : Normalized irradiance, $I / I_{\mathrm{STC}}$

I: Irradiance

l: Separation distance between PV systems

$N$ : Number of systems used for ensemble statistics

$p$ : Normalized power, $P / P_{\mathrm{s}}$

$P$ : Power

$t$ : Time over which measurement is taken, sliding time interval for average

v: Characteristic velocity of solar resource change.

\section{Greek Symbols}

$\Delta V$ : Deviation of grid voltage from nominal value

$\Pi$ : $\quad$ Perceptibility index

\section{Subscripts}

$I_{n}: \quad n^{\text {th }}$ value of irradiance in a dataset

$I_{\mathrm{rr}}: \quad$ Irradiance ramp rate

$I_{\text {STC }}: \quad$ Standard test condition irradiance

$\left(I_{\mathrm{rr}}\right)_{\mathrm{RMS}}$ : Root mean square of $I_{\mathrm{rr}}$

$P_{n}: \quad n^{\text {th }}$ value of power in a dataset

$P_{s}: \quad$ PV system nameplate value

$\Pi_{\mathrm{st}}: \quad$ Short-term perceptibility index

$\Pi_{\mathrm{lt}}: \quad$ Long-term perceptibility index

$\sigma_{\text {avg }}$ : Standard deviation in $\left\langle I_{\mathrm{rr}}>\right.$ where average is over $N$ observation locations

$\sigma_{1, N}: \quad$ Weighted average of standard deviation in each of individual observation location 1 through $N$.

\section{Data Availability}

Data is available upon request. Contact corresponding author to gain access.

\section{Conflicts of Interest}

The authors declare that they have no conflict of interest to report regarding the publication of this article.

\section{References}

[1] Solar Energy Industries Association (SEIA) \GTM Research, "U.S. solar market insight - 2016 year in review. Executive Summary," 2017, http://www.seia.org/research-resources/ solar-market-insight-report-2016-year-review.

[2] New York State Energy Research and Development Authority (NYSERDA), "Solar growth document: table of solar growth by region,” 2017, April 2017, https://www.nyserda.ny.gov/ solargrowth.

[3] M. Z. Jacobson, R. W. Howarth, M. A. Delucchi et al., "Examining the feasibility of converting New York State's all-purpose energy infrastructure to one using wind, water, and sunlight," Energ Policy, vol. 57, pp. 585-601, 2013.

[4] R. J. Broderick, M. J. Reno, K. Munoz-Ramos et al., Alternatives to the 15\% rule, SAND2015-10099, Sandia National Laboratory, Albuquerque, NM, 2015.

[5] Joint Utilities of New York, "Supplemental distributed system implementation plan. Case 16-M-0411 - in the matter of distributed system implementation plans," 2016.

[6] Pacific Gas and Electric Company Electric (PG\&E), "Distribution resources plan. Pursuant to Public Utilities Code 769 and California Public Utilities Commission Order Instituting Rulemaking 14-08-013," 2015.

[7] Southern California Edison Company (SCE), "Distribution resources plan. Pursuant to Public Utilities Code 769 and California Public Utilities Commission Order Instituting Rulemaking 14-08-013.," 2015.

[8] A. Dubey and S. Santoso, "On estimation and sensitivity analysis of distribution circuit's photovoltaic hosting capacity," IEEE Transactions on Power Systems, vol. 32, no. 4, pp. 2779-2789, 2017.

[9] S. Jothibasu and S. Santoso, "Sensitivity Analysis of Photovoltaic Hosting Capacity of Distribution Circuits," in IEEE Power \& Energy Society General Meeting, Boston, MA, 2016.

[10] E. Kern, E. M. Gulachenski, and G. A. Kern, "Cloud effects on distributed photovoltaic generation: slow transients at the Gardner, Massachusetts photovoltaic experiment," IEEE Transactions on Energy Conversion, vol. 4, no. 2, pp. 184190, 1989.

[11] C. Hansen, J. Stein, and A. Ellis, Statistical Criteria for Characterizing Irradiance Time Series, SAND2010-7314, Sandia National Laboratory, Albuquerque, NM, 2010.

[12] K. Lappalainen and S. Valkealahti, "Recognition and modelling of irradiance transitions caused by moving clouds," Solar Energy, vol. 112, pp. 55-67, 2015.

[13] M. Lave and J. Kleissl, "Cloud speed impact on solar variability scaling - application to the wavelet variability model," Solar Energy, vol. 91, pp. 11-21, 2013.

[14] O. Perpinan and E. Lorenzo, "Analysis and synthesis of the variability of irradiance and PV power time series with the wavelet transform," Solar Energy, vol. 85, no. 1, pp. 188-197, 2011.

[15] M. Reno and J. Stein, "Using cloud classification to model solar variability," in ASES National Solar Conference, Baltimore, MD, 2013.

[16] S. Roy, "Statistical estimates of short duration power generated by a photovoltaic unit in environment of scattered cloud cover," Energy, vol. 89, pp. 14-23, 2015.

[17] CAT Projects \& Australian Renewable Energy Agency (ARENA), "Investigating the Impact of Solar Variability on Grid Stability,” 2015. 
[18] B. Hodge, M. Hummon, and K. Orwig, "Solar ramping distributions over multiple timescales and weather patterns," in 10th International Workshop on Large-Scale Integration of Wind Power into Power Systems, Aarhus, Denmark, 2011.

[19] D. Lew, B. Brinkman, E. Ibanez et al., The Western Wind and Solar Integration Study Phase 2, NREL, 2013.

[20] A. Woyte, R. Belmans, and J. Nijs, "Fluctuations in instantaneous clearness index: analysis and statistics," Solar Energy, vol. 81, no. 2, pp. 195-206, 2007.

[21] R. Perez, S. Kivalov, J. Schlemmer, K. Hemker Jr., and T. E. Hoff, "Short-term irradiance variability: preliminary estimation of station pair correlation as a function of distance," Solar Energy, vol. 86, no. 8, pp. 2170-2176, 2012.

[22] G. Lohmann, A. H. Monahan, and D. Heinemann, "Local short-term variability in solar irradiance," Atmospheric Chemistry and Physics, vol. 16, no. 10, pp. 6365-6379, 2016.

[23] M. Lave and J. Kleissl, "Solar variability of four sites across the state of Colorado," Renewable Energy, vol. 35, no. 12, pp. 2867-2873, 2010.

[24] M. Lave, J. Kleissl, and E. Arias-Castro, "High-frequency irradiance fluctuations and geographic smoothing," Solar Energy, vol. 86, no. 8, pp. 2190-2199, 2012.

[25] J. Bank and B. Mather, "Analysis of the Impacts of DistributedConnected PV Using High-Speed Data Sets," in National Renewable Energy Laboratory, Golden, CO, 2013.

[26] H. Pezeshki, P. J. Wolfs, and G. Ledwich, "Impact of high PV penetration on distribution transformer insulation life," IEEE Transactions on Power Delivery, vol. 29, no. 3, pp. 12121220, 2014.

[27] R. Yan, B. Marais, and T. K. Saha, "Impacts of residential photovoltaic power fluctuation on on-load tap changer operation and a solution using DSTATCOM," Electric Power Systems Research, vol. 111, pp. 185-193, 2014.

[28] A. E. Curtright and J. Apt, "The character of power output from utility-scale photovoltaic systems," Progress in Photovoltaics: Research and Applications, vol. 16, no. 3, pp. 241-247, 2008.

[29] S. Shedd, B. Hodge, A. Florita, and K. Orwig, "A statistical characterization of solar photovoltaic power variability at small timescales," in 2nd Annual International Workshop on Inegration of Solar Power into Power Systems Conference, Lisbon, Portugal, 2012.

[30] J. Stein, C. Hansen, A. Ellis, and V. Chadliev, Estimating Annual Synchronized 1-Min Power Output Profiles from Utility-Scale PV Plants at 10 Locations in Nevada for a Solar Grid Integration Study, Sandia National Laboratory, Albuquerque, NM, 2011.

[31] J. Marcos, L. Marroyo, E. Lorenzo, D. Alvira, and E. Izco, "Power output fluctuations in large scale PV plants: one year observations with one second resolution and a derived analytic model," Progress in Photovoltaics: Research and Applications, vol. 19, no. 2, pp. 218-227, 2011.

[32] J. Marcos, M. Marroyo, E. Lorenzo, and M. Garcia, "Power output fluctuations in large PV plants," Renewable Energy and Power Quality, vol. 1, no. 10, pp. 1276-1281, 2012.

[33] M. Lave, A. Ellis, and J. S. Stein, Simulating Solar Power Plant Variability: A Review of Current Methods, SAND2013-4757, Sandia National Laboratories, Albuquerque, New Mexico, 2013.

[34] B. Mazumdar, M. Saquib, and A. K. Das, "An empirical model for ramp analysis of utility-scale solar PV power," Solar Energy, vol. 107, pp. 44-49, 2014.
[35] G. Ari and Y. Baghzouz, "Impact of High PV Penetration on Voltage Regulation in Electrical Distribution Systems," in Clean Electrical Power (ICCEP), Ischia, Italy, 2011.

[36] V. Disfani, P. Ubirata, and J. Kleissl, Model Predictive on-Load Tap Changer Control for High Penetration of PV Using Sky Imager Solar Forecast, California Solar Initiative R\&D Program, 2015.

[37] M. Ebad and W. M. Grady, "An approach for assessing highpenetration PV impact on distribution feeders," Electric Power Systems Research, vol. 133, pp. 347-354, 2016.

[38] N. P. Technologies, Identification of Low-Impact Interconnection Sites for Wholesale Distributed Photovoltaic Generation Using Energynet Power Simulation, California Energy Commission, 2011.

[39] W. Peng, S. Haddad, and Y. Baghzouz, "Improving Power Quality in Distribution Feeders with High PV Penetration through Inverter Controls," in CIRED Workshop, Lisbon, 2012.

[40] M. Reno, K. Coogan, R. Broderick, J. Seuss, and S. Grijalva, "Impact of PV variability and ramping events on distributed voltage regulation equipment," in IEEE Photovoltaic Specialists Conference, Denver, CO, 2014.

[41] B. Smith and D. Armstead, "Local and regional PV power variability in the Northeastern US, solar ramp rates and irradiance decorrelation with distance," 2020, Under review.

[42] T. Hoff and R. Perez, "Quantifying PV power output variability,” Solar Energy, vol. 84, no. 10, pp. 1782-1793, 2010.

[43] C. Maxey and A. Andreas, Rotating shadowband radiometer (RSR), Oak Ridge National Laboratory (ORNL), Oak Ridge, Tennessee, 2007, (data); NREL Report No. DA-5500-56512.

[44] A. Andreas and T. Stoffel, "Elizabeth City State University. Elizabeth City, North Carolina (data); NREL Report No. DA5500-56517," 1985.

[45] A. Andreas and T. Stoffel, "Bluefield State College. Bluefield, West Virginia (data); NREL Report No. DA-5500-56519," 1985.

[46] T. Key, L. Rogers, and B. York, Recommendations for harmonizing distributed generation interconnection practices: technical review processes in NY State final report, Electric Power Research Institute, Knoxville, Tennessee, 2017.

[47] California Public Utilities Commission (CPUC), "Electric rule 21," 2016, http://www.cpuc.ca.gov/Rule21/.

[48] Federal Energy Regulatory Commission (FERC), "Small Generator Interconnection Agreements and Procedures. [Docket Nos. RM13-2-000; Order No. 792], 18 CFR Part 35,” 2013.

[49] Massachusetts Department of Energy Resources (MDOER), "Distributed generation and interconnection in Massachusetts," 2017, https://sites.google.com/site/massdgic/home/ interconnection.

[50] State of New York Public Service Commission (NYS PSC), "Order modifying standardized interconnection requirements. CASE 15-E-0557, Issued and Effective March 18, 2016,” 2016.

[51] Institute of Electrical and Electronics Engineers (IEEE), "IEEE recommended practice for the analysis of fluctuating installations on power system. IEEE Std 1453-2015 (Revision of IEEE Std 1453-2011)," 2015.

[52] R. Broderick, J. Quiroz, M. Reno, A. Ellis, J. Smith, and R. Dugan, Time series power flow analysis for distribution connected $P V$ generation, Sandia National Laboratories, (SAND2013-0537), 2013. 
[53] Institute of Electrical and Electronics Engineers (IEEE), "IEEE guide for conducting distribution impact studies for distributed resource interconnection. IEEE Std 1547.7-2013,” 2013.

[54] Institute of Electrical and Electronics Engineers (IEEE), "IEEE standard for interconnecting distributed resources with electric power systems. IEEE Std 1547-2003," 2003.

[55] Institute of Electrical and Electronics Engineers (IEEE), "IEEE recommended practice and requirements for harmonic control in electric power systems. IEEE Std 519-2014 (Revision of IEEE Std 519-1992)," 2014.

[56] Institute of Electrical and Electronics Engineers (IEEE), "IEEE recommended practice and requirements for harmonic control in electric power systems. IEEE Std 519-1992 (Revision of IEEE Std 519-1981)," 1992.

[57] American National Standards Institute (ANSI), "American National Standard for electric power systems and equipmentvoltage ratings (60 hertz). ANSI C84.1-2016," 2016.

[58] B. Korpics and K. S. White, "Pursuant to Public Utilities Code 769 and California Public Utilities Commission Order Instituting Rulemaking 14-08-013". 